\title{
J. R. R. TOLKIEN Y LA TRADUCCIÓN: «THE NOMENCLATURE OF THE LORD OF THE RINGS» Y SU APROXIMACIÓN A LA REFLEXIÓN TRADUCTOLÓGICA CONTEMPORÁNEA
}

\author{
MARÍA DEL CARMEN MORENO PAZ \\ Universidad de Córdoba \\ 102mopam@uco.es \\ ORCID: 0000-0002-2850-5057
}

\section{RESUMEN}

Tras el éxito de The Lord of the Rings (1954-1955), las primeras traducciones de la obra de Tolkien empezaron a propagarse por todo el mundo. Sin embargo, Tolkien, filólogo y traductor de obras del inglés antiguo e inglés medio, se vio en la necesidad de indicar cómo traducir los nombres ficcionales presentes en su obra, integrados en una complicada red genealógica de lenguas tanto reales como ficcionales. De estas notas sobre la traducción («The Nomenclature of The Lord of the Rings»), además de desprenderse indicaciones filológicas para la traducción de su obra, se puede analizar asimismo la postura de Tolkien sobre la traducción, que puede a su vez relacionarse con la reflexión traductológica actual sobre los diferentes métodos de traducir. En efecto, se observa que la postura de Tolkien pasa de ser en un principio marcadamente «extranjerizante»o «hacia el autor» (siguiendo la terminología de Venuti y Schleiermacher) para finalmente defender un método más «naturalizante» o «hacia el receptor». Sin embargo, conviene tener en cuenta la importancia de la función y el contexto de producción, por lo que es preciso actualizar la postura de Tolkien sobre la traducción en relación con teorías descriptivas que negocian el valor de la equivalencia.

PALABRAS-CLAVE: The Lord of the Rings, J. R. R. Tolkien, equivalencia, traducción extranjerizante, traducción naturalizante, problemas de traducción.

\section{J. R. R. TOLKIEN AND TRANSLATION: “THE NOMENCLATURE OF THE LORD OF THE RINGS" IN RELATION TO CURRENT APPROACHES IN TRANSLATION STUDIES}

\section{ABSTRACT}

After the success of The Lord of the Rings (1954-1955), the first translations of Tolkien's work into other languages began to spread all over the world. However, Tolkien (philologist and translator of works from Old and Middle English) considered it necessary to publish some guidelines on how to translate the fictional names in his work, for whose creation he had developed a complex linguistic network of both real and fictional languages. These notes, published under the title "The Nomenclature of The Lord of the Rings", not only provide useful philological information for the translation of his work, but also allow to understand Tolkien's opinion about translation methods, which can also be related to current theories in translation studies. It is indeed observed that Tolkien's position changes through time, since he first defends a foreignizing, author-oriented translation (according to the terminology of Venuti and Schleiermacher). However, in his later writings he justifies a more domesticating or targetoriented translation. Nevertheless, it is also important to bear in mind the relevance of the translation's function and context of production, which justifies an analysis of Tolkien's view on 
translation in relation to descriptive theories that negotiate the value of translation equivalence.

KEYWORDS: The Lord of the Rings, J. R. R. Tolkien, equivalence, foreignizing translation, domesticating translation, translation problems.

\section{INTRODUCCIÓN: LA MOTIVACIÓN FILOLÓGICA DE LA OBRA DE TOLKIEN}

Este trabajo pretende abordar una cuestión a menudo olvidada al estudiar las obras de J. R. R. Tolkien y sus traducciones a otras lenguas: la propia opinión del autor sobre cómo traducir su obra. Tolkien, escritor inglés conocido sobre todo por sus obras de ficción como The Lord of the Rings (1954-1955) o The Hobbit (1937), fue también filólogo y profesor de Oxford y traductor al inglés moderno de obras procedentes del inglés antiguo o el inglés medio como Beowulf o Sir Gawain and the Green Knight, por lo que contaba con un gran bagaje lingüístico y filológico que trató de reflejar en sus consideraciones acerca del correcto trasvase de su obra a otras lenguas.

Dada, además, la motivación filológica del autor para escribir su obra ficcional cabe asumir la importancia que posee la creación de la nomenclatura y la atención especial que merece en la traducción a otras lenguas. La conexión entre la pasión de Tolkien por la filología y su obra literaria se encuentra reflejada en escritos como su carta n. ${ }^{-131}$, dirigida a Milton Waldman, en la que Tolkien reconoce la importancia de las lenguas en su obra (Carpenter 2006: 143144):

In order of time, growth and composition, this stuff began with me -though I do not suppose that that is of much interest to anyone but myself. I mean, I do not remember a time when I was not building it. Many children make up, or begin to make up, imaginary languages. I have been at it since I could write. But I have never stopped, and of course, as a professional philologist (especially interested in linguistic aesthetics), I have changed in taste, improved in theory, and probably in craft. Behind my stories is now a nexus of languages (mostly only structurally sketched). But to those creatures which in English I call misleadingly Elves are assigned two related languages more nearly completed, whose history is written, and whose forms (representing two different sided of my own linguistic taste) are deduced scientifically from a common origin. Out of these languages are made nearly all the names that appear in my legends. This gives a certain character (a cohesion, a consistency of linguistic style, and an illusion of historicity) to the nomenclature, or so I believe, that is markedly lacking in other comparable things. ${ }^{1}$

1 «Por lo que respecta a la época, el desarrollo y la composición, todo esto empezó conmigo (aunque supongo que esto no interesa demasiado a nadie salvo a mí). Quiero decir, no recuerdo una época en la que no lo estaba construyendo. Muchos niños inventan, o comienzan a inventar, lenguas imaginarias. Yo me he dedicado a eso desde que sé escribir. Pero nunca lo he dejado y, por supuesto, como filólogo profesional (particularmente interesado en la estética lingüística), mis gustos han cambiado, mi teoría ha mejorado y, probablemente, también mi destreza. Detrás de mis historias hay ahora una conexión entre las lenguas (más que nada solo esbozada estructuralmente). Pero a aquellas criaturas que en inglés llamo confusamente Elfos he asignado dos lenguas relacionadas casi completadas, cuya historia está escrita, y cuyas 
Asimismo, en su carta n. ${ }^{\circ} 165$ a Houghton Mifflin, Tolkien recalca que su obra posee una inspiración «fundamentalmente lingüística», aunque que un profesor de filología escriba cuentos de hadas y romances pueda parecer una aberración a los académicos universitarios (Carpenter 2006: 219-220). En su carta n. ${ }^{-}$205, dirigida a su hijo Christopher, Tolkien declara que se siente un «filólogo puro»: afirma que le gusta la historia, pero sobre todo cuando esta arroja luz sobre las palabras y los nombres. También confiesa a su hijo que nadie le cree cuando manifiesta que The Lord of the Rings es un intento de crear un mundo en el que pueda tener cabida una lengua que se adecue a su placer estético (Carpenter 2006: 264-265). Para el autor y profesor de Oxford, por tanto, su obra ficcional supone también un trabajo filológico (no solo por la creación de lenguas inventadas, sino por el uso de otras lenguas distintas del inglés), por lo que la elección de lenguas y nombres responde a una intención determinada y meditada que no puede obviarse al enfrentarse a su traducción, ya que se trata de un elemento esencial y característico de esta obra.

Tras el éxito de su obra The Lord of the Rings, las primeras traducciones a otros idiomas empezaron a propagarse por todo el mundo, por lo que el autor, receloso de su obra y de la nomenclatura que había creado para denominar su mundo ficcional, se vio en la necesidad de indicar a los traductores cómo traducir la gran cantidad de nombres ficcionales presentes en su libro, procedentes tanto de lenguas ficcionales como reales (como el inglés o el nórdico antiguos). Estas consideraciones sobre la traducción se manifiestan en sus cartas y otros escritos, pero sobre todo en el manuscrito «The Nomenclature of The Lord of the Rings», en el que explica a los traductores cómo deben traducir su nomenclatura desde un punto de vista filológico y atendiendo a la etimología de las palabras.

Por consiguiente, las páginas que siguen pretenden ilustrar la postura de Tolkien como filólogo con respecto a la traducción de su obra para relacionarla posteriormente con las principales corrientes traductológicas existentes en la actualidad y observar los problemas de traducción que presenta de manera específica The Lord of the Rings, así como la utilidad de dicha guía para la traducción desde el punto de vista de los estudios de traducción actuales.

\section{PROBLEMAS DE TRADUCCIÓN DE THE LORD OF THE RINGS}

En líneas generales, la principal dificultad que plantea la traducción de la obra de Tolkien reside en la compleja red lingüística creada por el autor para otorgar profundidad y verosimilitud a su mundo ficcional, y que se manifiesta de

formas (que representan dos lados distintos de mi propio gusto lingüístico) pueden deducirse científicamente de un origen común. A partir de esas lenguas se han creado casi todos los nombres que aparecen en mis leyendas. Esto da a un personaje cohesión, coherencia en el estilo lingüístico y una ilusión de historicidad a la nomenclatura, o al menos así lo creo, de la que carecen de manera evidente otras cosas comparables» [traducción propia]. 
manera específica en su nomenclatura (tanto a partir de lenguas reales como de lenguas ficcionales). Así lo reconoce el autor, por ejemplo, en su carta n. ${ }^{\circ}$ 144, dirigida a Naomi Mitchison (que había leído y revisado el manuscrito de The Lord of the Rings), en la que Tolkien resalta de nuevo la importancia de la lengua en su obra literaria y la relación entre algunas de las principales lenguas utilizadas en su obra (Carpenter 2006: 175):

\begin{abstract}
Anyway 'language' is the most important, for the story has to be told, and the dialogue conducted in a language; but English cannot have been the language of any people at that time. What I have, in fact, done is to equate the Westron or wide-spread Common Speech of the Third Age with English; and translate everything, including names such as The Shire, that was in the Westron into English terms, with some differentiation of the style to represent dialectal differences. Languages quite alien to the C. S. have been left alone. Except for a few scraps in the Black Speech of Mordor, and a few names and a battle-cry in Dwarvish, these are almost entirely Elvish (Eldarin). ${ }^{2}$
\end{abstract}

Concretamente, Tolkien revela que las lenguas relacionadas con el westron o lengua común presentaron un problema específico (Carpenter 2006: 175):

Languages, however, that were related to the Westron presented a special problem. I turned them into forms of speech related to English. Since the Rohirrim are represented as recent comers out of the North, and users of an archaic Mannish language relatively untouched by the influence of Eldarin, I have turned their names into forms like (but not identical with) Old English. The language of Dale and the Long Lake would, if it appeared, be represented as more or less Scandinavian in character; but it is only represented by a few names, especially those of the Dwarves that came from that region. These are all Old Norse Dwarf-names. ${ }^{3}$

Más allá de la relevancia que Tolkien otorga a los estilos y variedades lingüísticas para los diferentes pueblos de su obra ficcional, conviene destacar la importancia que otorgaba de manera particular a la creación de nombres para

2 «De cualquier modo, la 'lengua' es lo más importante, pues la historia debe ser contada y el diálogo guiado por una lengua; pero el inglés no hubiera podido ser la lengua de ningún pueblo en aquella época. Lo que he hecho, en efecto, es equiparar el westron, o la extendida lengua común de la Tercera Edad, con el inglés, y traducir todo, incluyendo nombres como La Comarca (The Shire), que estaban en westron en términos ingleses, con algunas diferencias estilísticas para representar las diferencias dialectales. Las lenguas distintas de la lengua común son un caso aparte. Excepto algunas muestras en la lengua negra de Mordor y algunos nombres y un grito de guerra en la lengua de los enanos, estas son casi exclusivamente élficas (Eldarin)» [traducción propia].

3 «Sin embargo, las lenguas emparentadas con el westron presentaron un problema especial. Las convertí en formas de discurso relacionadas con el inglés. Puesto que los Rohirrim se representan como llegados recientemente del norte y usan una lengua de hombres arcaica relativamente intacta a la influencia del eldarin, he transformado sus nombres en formas similares (pero no idénticas) al inglés antiguo. La lengua del Valle o del Lago Largo, si apareciera, tendría un carácter más o menos escandinavo, pero esto solo se muestra en unos cuantos nombres, especialmente aquellos de los enanos que proceden de esa región. Estos tienen todos nombres de enanos del nórdico antiguo» [traducción propia]. 
denominar los conceptos que formaban su mundo ficcional. A propósito de la creación, Carpenter (2016: 132) señala lo siguiente:

\begin{abstract}
When working to plan he would form all these names with great care, first deciding on the meaning, and then developing its form first in one language and subsequently in the other; the form finally used was most frequently that in Sindarin. However, in practice he was often more arbitrary. It seems strange in view of his deep love of careful invention, yet often in the heat of writing he would construct a name that sounded appropriate to the character without paying more than cursory attention to its linguistic origins. Later he dismissed many of the names made in this way as 'meaningless', and he subjected others to a severe philological scrutiny in an attempt to discover how they could have reached their strange and apparently inexplicable form. ${ }^{4}$
\end{abstract}

En su monografía Translating Tolkien (2005), Allan Turner analiza los problemas de traducción que plantean los elementos filológicos en la obra de Tolkien, así como los recursos de los que dispone el traductor para enfrentarse a ellos y poder solucionarlos. Algunos de los principales problemas para la traducción que cita Turner residen también en el propio aparato lingüístico que envuelve a la obra. En primer lugar, los hobbits se presentan como «mediadores culturales», ya que la tierra que habitan, The Shire, puede considerarse un calco de Inglaterra, así como su historia cultural y lingüística se asemeja a la historia del inglés (lo que se manifiesta en antropónimos y topónimos, por ejemplo). Por lo tanto, la identificación implícita de los hobbits con la Inglaterra rural plantea interrogantes sobre qué se considera familiar o exótico para el lector y cómo debe trasvasarse en la lengua meta. Al mismo tiempo, el contraste entre lo arcaico y lo moderno puede plantear la cuestión de qué grado de arcaísmo debe preservarse en el texto meta (Turner 2005: 15).

En cuanto a la presentación de la obra como una «pseudotraducción», es decir, como si la obra original fuera una supuesta traducción del westron al inglés moderno del autor de un libro escrito en la Tierra Media, Turner (2005: 37) indica que no supone un verdadero problema para la traducción, pero es necesario tener muy presente que este recurso forma parte del entramado lingüístico del mundo ficcional, ya que en el texto original la lengua de la traducción (el inglés moderno) representa el westron y existen lenguas relacionadas (como el inglés antiguo o el nórdico antiguo) a las que se recurre como una supuesta traducción de las lenguas de Rohan o las lenguas de los

4 «Cuando trabajaba en la organización formaba todos estos nombres con cuidado: primero decidía el significado y después desarrollaba su forma primero en una lengua y posteriormente en la otra; la forma que solía usar finalmente era la del sindarin. Sin embargo, en la práctica era a menudo más arbitrario. Resulta extraño en vista de su profunda afición por la invención minuciosa; sin embargo, a menudo, en el ardor del momento de la escritura, construía un nombre que sonaba apropiado para un personaje prestando poca atención a sus orígenes lingüísticos. Después rechazaba muchos de los nombres construidos así por "carecer de sentido" y sometía otros a un serio escrutinio filológico en un intento de descubrir cómo podían haber alcanzado su extraña y aparentemente inexplicable forma» [traducción propia]. 
hombres del norte, emparentadas con el westron del mismo modo que el inglés antiguo está relacionado con el inglés moderno.

Otro problema relacionado con la traducción de esta obra, según Turner (2011: 11-12), es la falta de información de la que disponían los primeros traductores, por ejemplo, en el momento de la aparición de The Lord of the Rings. En estos casos, su obra póstuma The Silmarillion, que contiene gran cantidad de información (no solo sobre el argumento, sino de carácter filológico), no se había publicado. Además, en el caso de los dos primeros volúmenes de The Lord of the Rings, tampoco se conocían los Apéndices que aparecieron con el tercer volumen, en el que se justifica la etimología de muchos nombres y se aporta información para la traducción.

Es posible constatar, por tanto, la relevancia y complejidad de las relaciones lingüísticas creadas por Tolkien en su obra, que suponen a su vez un elemento esencial de su valor literario. Sin embargo, esta red lingüística que parte del inglés moderno como lengua vehicular del texto supone un evidente problema de traducción, ya que el traductor ha de decidir qué grado de apropiación o acercamiento cultural y lingüístico conviene emplear en la traducción. Tratándose, además, de la obra de un filólogo experto en lenguas antiguas y creador de sus propias lenguas ficcionales, el traductor debe también prestar especial atención a la etimología de los nombres utilizados.

\section{CONSIDERACIONES DE TOLKIEN A PROPÓSITO DE LA TRADUCCIÓN DE SU OBRA}

Resulta lógico suponer que, tras el éxito de The Lord of the Rings en Reino Unido y Estados Unidos, numerosos países se interesaran en la obra de Tolkien y en traducirla a sus respectivas lenguas para su publicación. No obstante, y al contrario de lo que acontece con otros autores, a Tolkien la idea de que su obra fuera traducida a otras lenguas le producía cierta desconfianza, ya que consideraba que la traducción de los nombres, sobre todo, era sumamente difícil y se perderían muchos matices y riqueza al trasvasarla a otras lenguas. Por ello, se mostró a menudo crítico con las traducciones y exigió que se le consultara sobre el proceso de traducción.

La importancia que otorga Tolkien a la traducción se manifiesta también en el propio Apéndice $F$ que aparece al final del tercer volumen de The Lord of the Rings, ya que la segunda parte de este se titula «On Translation». Este apéndice forma parte del texto ficcional, puesto que se incluye como un comentario o aclaración filológica incluida por el traductor ficcional del Red Book del Westron o Lengua Común al inglés moderno. En él, el traductor ficcional justifica algunas de sus decisiones (lo que arroja luz sobre la creación de los nombres en Tolkien y su importancia para la traducción). Así, se puntualiza que se utiliza el inglés moderno para representar la lengua común de la Tierra Media, de modo que las variedades o dialectos de la lengua común (como el que hablan los hobbits o los hombres de Gondor) se ha reflejado con 
distintas variedades dialectales o registros del inglés moderno. Así, los hobbits recurren a un dialecto más bien rural, mientras que en Gondor y Rohan se habla una lengua arcaica y más formal. Los nombres procedentes de Rohan se han «traducido» al inglés antiguo, ya que en Rohan hablaban una lengua arcaica emparentada con la de los hobbits. Por otra parte, las lenguas distintas de la lengua común se han mantenido en su forma original en el libro (Tolkien 2007: 1133-1136).

En cuanto a las primeras traducciones de la obra de Tolkien, como relata Carpenter (2016: 299-300), tras el éxito de The Lord of the Rings, la editorial Allen \& Unwin empezó a negociar la traducción de la obra de Tolkien a otras lenguas. El primer resultado fue la traducción al neerlandés en 1956, después de que Tolkien hubiera criticado duramente los primeros intentos del traductor de traducir a su lengua algunos de los nombres de la obra.

Concretamente, en la carta n. ${ }^{\circ} 188$ de Tolkien (datada de abril de 1956), los editores Allen \& Unwin informan a Tolkien de que han firmado un acuerdo para una traducción al neerlandés de The Lord of the Rings. En ella, Tolkien responde que cualquier autor vivo siente una preocupación e interés profundo e inmediato por la traducción de su obra. Asimismo, añade que la traducción de The Lord of the Rings constituye una tarea formidable, que no sabe cómo puede llevarse a cabo satisfactoriamente sin la ayuda del autor, que él se ofrece a proporcionar. Se refiere, concretamente, a palabras que no se encuentran en los diccionarios o que requieren conocimientos de inglés antiguo.

Por otro lado, Tolkien aprovecha para señalar que espera evitar una repetición similar a la sufrida después de la traducción al sueco de The Hobbit, en la que el traductor se tomó numerosas licencias y libertades sin su aprobación o consentimiento. ${ }^{5}$ Con respecto a The Lord of the Rings, afirma que guarda el texto aún con más recelo y que no aprobaría tales licencias o alteraciones a no ser que se le consultara o que él las aprobara (Carpenter 1981: 248-249).

Como se relata después en la carta n. ${ }^{0}$ 190, en junio de 1956, la editorial Allen \& Unwin envió una lista de traducciones de topónimos al neerlandés de The Lord of the Rings para que Tolkien aprobara la versión del traductor. En esta carta, Tolkien (Carpenter 1981: 249-250) responde que en principio se opone fervientemente a la traducción de toda la nomenclatura en general:

In principle I object as strongly as possible to the 'translation' of the nomenclature at all. I wonder why a translator should think himself called or entitled to do any such thing. That this is an 'imaginary' world does not give him any right to remodel it according to

\footnotetext{
${ }^{5}$ Estas licencias y libertades, según Tolkien, se debieron a que el traductor no debió adaptar los nombres al sueco.
} 
his fancy, even if he could in a few months create a new coherent structure which it took me years to work out. ${ }^{6}$

A continuación, pone como ejemplo que, si hubiera presentado a los hobbits como hablantes de italiano, ruso o chino, se habrían mantenido los nombres, del mismo modo que si hubiera identificado The Shire con algún lugar de Inglaterra. No obstante, reafirma que, puesto que se trata de un lugar imaginario o ficcional, la nomenclatura es aún más importante que en una novela histórica (si bien no justifica el porqué). Señala, a propósito de The Shire, que se basa en la Inglaterra rural y no en otro país, por lo que el traductor no debería tratar de alterar el color local al trasvasarlo a otra lengua. Critica, por tanto, que el traductor de neerlandés adapte cualquier topónimo. Asimismo, añade que su postura es la misma con respecto a los antropónimos, o con palabras como hobbit $\mathrm{u}$ orc, que deben permanecer sin alterar en cualquier lengua (Carpenter 1981: 250-251). En definitiva, el autor considera que cualquier nombre (ya sea en inglés moderno o en otra lengua real o ficcional) debe mantenerse sin modificaciones, aunque este tenga un significado reconocible en el texto original.

De nuevo, con respecto a la traducción al polaco de The Lord of the Rings, para la que la traductora había pedido asesoramiento a Tolkien, el autor responde en su carta n. ${ }^{\circ} 217$ que no tiene tiempo para escribir todas las notas que ella requiere, pero su consejo general es que se evite la traducción o alteración de los nombres todo lo que sea posible, ya que debe preservarse el color local inglés. Sugiere que, en todo caso, al final de la obra traducida se incluya un glosario con explicaciones en polaco sobre los nombres en inglés (Carpenter 1981: 299).

Por otro lado, como se relata en la carta posterior n. ${ }^{\circ}$ 204, en diciembre de 1957 Allen \& Unwin proporcionaron información sobre la traducción al sueco de The Lord of the Rings. En esta carta, Tolkien también se muestra irritado con la lista de nombres que el traductor al sueco había modificado y que justificaba a Tolkien, que en cualquier caso veía injustificable una traducción. Sugiere que, además de leer los Apéndices, se le consulte para otras traducciones en un estadio más temprano del proceso de traducción. Declara, además, que se da cuenta de que debería existir un índice o glosario para la traducción de los nombres para poder solucionar estas cuestiones (Carpenter 1981: 262-264).

\footnotetext{
6 «En principio, me opongo firmemente a la "traducción" de la nomenclatura en general. Me pregunto por qué un traductor debería creerse autorizado o con derecho a hacer tal cosa. Que se trate de un mundo "imaginario" no le da ningún derecho a remodelarlo a su antojo, aunque pudiera crear una nueva estructura coherente en unos pocos meses, que a mí me llevó años cuadrar» [traducción propia].
} 


\subsection{La publicación de «The Nomenclature of The Lord of the Rings»}

Tras las primeras traducciones al neerlandés y el sueco publicadas entre 1956 y 1957, Tolkien se opuso fervientemente a la alteración de los nombres que se había llevado a cabo en ellas. Para él, la manera más correcta de traducir su obra pasaba por mantener los mapas y nomenclatura como en el texto original tanto como fuera posible. No obstante, al final Tolkien acabó asumiendo que podría haber más traductores que, como los de neerlandés y sueco, consideraran que debía cambiarse la nomenclatura, por lo que tomó la iniciativa $\mathrm{y}$, en lugar de insistir en la no traducción de sus nombres, trató de influir en las decisiones de los traductores a través de un documento explicativo. Este documento se fotocopió por sus editores Allen \& Unwin y se envió a los distintos traductores de The Lord of the Rings con el propósito de que sirviera como ayuda y guía para la traducción de los nombres. Tras la muerte de Tolkien, este documento fue editado por su hijo Christopher y publicado en A Tolkien Compass (1975) con el título "Guide to the Names in The Lord of the Rings». Posteriormente, en el volumen de Hammond y Scull The Lord of the Rings: A Reader's Companion se lleva a cabo una nueva transcripción del documento corregido por Tolkien, haciendo también referencia a una versión anterior del manuscrito, y se titula «The Nomenclature of The Lord of the Rings» (Hammond y Scull 2005: 751-752).

El texto de Tolkien comienza indicando que todos los nombres que no se incluyen en la lista deben mantenerse sin alterar en cualquier lengua de traducción, a excepción de las flexiones propias del plural. En este sentido, insta a los futuros traductores de su obra a leer el Apéndice F de The Lord of the Rings, en el que se indica que el inglés moderno representa la lengua común del mundo ficcional, por lo que la lengua de la traducción debe reemplazar al inglés moderno como equivalente de la lengua común, de modo que todos los nombres en inglés deben traducirse en la lengua de la traducción de acuerdo con su significado. A propósito de estos nombres, Tolkien señala que la mayoría no debería ofrecer problemas para trasvasar el significado, especialmente en el caso de aquellas lenguas con un origen germánico relacionadas con el inglés, tales como el neerlandés, el alemán o las lenguas escandinavas, y cita los ejemplos de nombres como Black Country, Battle Plain, Dead Marshes, etc. Sin embargo, sostiene que algunos nombres pueden resultar más complicados de traducir, ya que el autor ficcional del texto (que representa Tolkien) actúa como un traductor del élfico, por lo que en la obra aparecen nombres tanto en élfico como en sus equivalentes en inglés moderno, que intentan imitar los sonidos del élfico. Cita el ejemplo de Rivendell como equivalente en inglés del élfico Imladris. En casos como este, Tolkien recomienda traducir los nombres en la lengua de la traducción, puesto que mantenerlos como en el texto original alteraría el esquema de la nomenclatura e introduciría un elemento sin explicación en la historia lingüística que se trata de reproducir en la obra. No 
obstante, indica que los traductores que se enfrenten a su obra son libres de crear un nombre en la lengua de la traducción adecuado en cuanto al sentido o a la topografía (Hammond y Scull 2005: 751-752).

Asimismo, Tolkien señala como otra dificultad de la traducción el nombre de personajes y lugares que, especialmente en el caso de los nombres ligados a The Shire, tienen una forma inglesa y carecen de significado reconocible, a pesar de que contienen elementos obsoletos o dialectales y pueden resultar obscuros en cuanto a su significado. Para estos casos, Tolkien sugiere que lo deseable es que los futuros traductores tengan conocimiento de la nomenclatura de antropónimos y topónimos prototípica de la lengua de la traducción, así como de palabras dialectales o arcaicas. Por tanto, sostiene que el documento que presenta como guía para la traducción pretende, en este caso, ayudar a los potenciales traductores de su obra a distinguir entre invenciones llevadas a cabo a partir de elementos del inglés moderno (como Rivendell o Snowmane) y nombres reales en inglés, independientemente de su historia, que sería conveniente trasvasar en el texto meta con elementos equivalentes de carácter arcaico u obscuro (Hammond y Scull 2005: 752). Un ejemplo de este tipo podría ser Appledore, que Tolkien indica que es una palabra arcaica para «manzano», por lo que debería traducirse en otras lenguas tratando de emplear una palabra con connotaciones similares (Hammond y Scull 2005: 753).

Uno de los elementos que más llama la atención al leer este manuscrito es el hecho de que Tolkien defienda siempre trasvasar el sentido en el caso de nombres que poseen contenido semántico. Así, por ejemplo, en el caso de Baggins, Tolkien indica que debe traducirse el elemento bag, pero además los traductores deben emplear este mismo elemento para traducir el topónimo BagEnd. Lo mismo ocurre con los nombres que contienen el elemento buck (como Brandybuck o Buckland), en los que debe traducirse dicho elemento de la misma forma en todos los casos para preservar la coherencia (Hammond y Scull 2005: 753-754). Asimismo, cuando se trata de un nombre real en inglés, pero que posee contenido semántico reconocible en la lengua original, Tolkien sugiere traducirlo, empleando un elemento existente en el texto meta si es posible. Así, por ejemplo, Bracegirdle es un apellido real inglés, aunque se usa en el texto original en referencia a la tendencia de los hobbits a engordar y ajustarse el cinturón. Tolkien recomienda, por lo tanto, traducir el significado, aunque no es necesario que sea un apellido real en la lengua meta. Puede observarse, por lo tanto, cómo el autor cambia su opinión al respecto de la preservación del «color local inglés» a favor de la transmisión del sentido para el receptor.

Este documento resulta sin duda de gran utilidad puesto que Tolkien explica el origen y la forma de creación de gran parte de la nomenclatura de su obra, así como los elementos imprescindibles que considera que deben traducirse. Por ejemplo, explica que Cotton se basa en el elemento cot («cabaña o morada modesta») y -ton, un elemento común en topónimos ingleses que 
implica un acortamiento de town ('pueblo'). Por tanto, debe evitarse a toda costa la asociación con la palabra cotton ('algodón') (Hammond y Scull 2005: 755).

Por otro lado, en los casos en los que el nombre no posee un significado reconocible en la lengua meta o está formado a partir de lenguas distintas del inglés, como ocurre con Ent (que significa 'gigante' en inglés antiguo), Tolkien recomienda que no se altere en el texto meta (Hammond y Scull 2005: 756). En ciertos casos, no obstante, acepta que pueda llevarse a cabo una adaptación morfológica de acuerdo con el sistema de la lengua meta. Por ejemplo, en el caso de Gamgee, puesto que se trata de un nombre poco frecuente en inglés de origen desconocido, es posible adaptarlo a la ortografía de la lengua meta (Hammond y Scull 2005: 758) Otro ejemplo es Took, que no posee un origen conocido y puede adaptarse fonéticamente (Hammond y Scull 2005: 764). Sin embargo, en los casos en los que se produce en el texto original una adaptación al inglés moderno de elementos procedentes del inglés antiguo, Tolkien sugiere que la mejor opción es recurrir a los elementos originales en inglés antiguo; así, por ejemplo, Shadowfax debe traducirse como Scadufax y Snowmane como Snowmana (Hammond y Scull 2005: 762-763).

Resulta innegable, pues, la utilidad de este documento para la traducción de su obra a todas las lenguas, debido a la gran cantidad de información filológica y etimológica que proporciona el autor sobre su nomenclatura para aquellos traductores que deban hacer frente a la traducción de The Lord of the Rings (en muchos casos, además, sugiere traducciones para lenguas como el alemán, sueco o neerlandés). Puede observarse, además, el cambio de postura con respecto a sus escritos previos, dado que adquiere conciencia sobre la importancia de la transmisión del sentido, aunque esto conlleve una cierta pérdida de «color local».

\section{LA POSTURA DE TOLKIEN EN RELACIÓN CON LA REFLEXIÓN TRADUCTOLÓGICA}

A pesar de que Tolkien no se adscribe a ninguna corriente traductológica de manera directa (ya que se trata, además, de una disciplina que ha desarrollado su teoría de manera autónoma a la filología en las últimas décadas), es posible relacionar sus consideraciones filológicas a propósito de la traducción de su obra con determinados postulados traductológicos actuales. En líneas generales, en los estudios de traducción se han establecido tradicionalmente dos métodos de traducción opuestos para alcanzar la equivalencia traductora: la «traducción literal» (que privilegia la forma del texto original) y la «traducción libre» (que privilegia el sentido y la naturalidad del texto meta). No obstante, pueden encontrarse teorías más actuales que intentan conciliar ambas posturas y proponen una clasificación más exhaustiva y condicionada por diferentes factores pragmáticos como la intención, el contexto comunicativo, la función y el encargo de traducción. 
La dicotomía tradicional entre forma y sentido, o entre «traducción libre» $\mathrm{y}$ «traducción literal», puede remontarse a los primeros escritos sobre reflexión teórica en traducción de Cicerón o San Jerónimo, aunque en la actualidad contemporánea esta división binaria se debe en gran parte a la oposición metodológica expuesta por Schleiermacher que, en una conferencia de 1813, y a propósito de los métodos de traducción que pueden llevarse a cabo en la traducción, apunta lo siguiente (la traducción al español corresponde a García Yebra 2000: 47):

\begin{abstract}
Aber nun der eigentliche Übersetzer, der diese beiden ganz getrennten Personen, seinen Schriftsteiler und seinen Leser, wirklich einander zuführen, und dem letzten, ohne ihn jedoch aus dem Kreise seiner Muttersprache heraus zu nötigen, zu einem möglichst richtigen und vollständigen Verständnis und Genuß des ersten verhelfen will, was für Wege kann er hiezu einschlagen? Meines Erachtens gibt es deren nur zwei. Entweder der Übersetzer läßt den Schriftsteller möglichst in Ruhe, und bewegt den Leser ihm entgegen; oder er läßt den Leser möglichst in Ruhe und bewegt den Schriftsteller ihm entgegen. ${ }^{7}$
\end{abstract}

En este sentido, Schleiermacher (1999: 49) afirma que estas dos opciones son tan diferentes que solo es posible decantarse por una, ya que una mezcla de ambas produciría un resultado insatisfactorio y un fracaso de este acercamiento entre el lector y el escritor, y muestra su preferencia por la primera opción, según la cual el lector debería ir al encuentro del autor.

Para Berman (1999: 25-29), la traducción que privilegia el sentido a la forma se caracteriza por ser culturalmente etnocéntrica, literalmente hipertextual y filosóficamente platónica. El autor habla de traducción etnocéntrica como un método ampliamente extendido en Occidente, que se caracteriza por acercar todo a la cultura propia, a sus normas y valores, y considera que todo lo que se sitúa fuera de ella (lo extranjero) es negativo o simplemente apto para anexarse o adaptarse y aumentar la cultura receptora. En otras palabras, explica esta estrategia del siguiente modo (Berman 1999: 34):

La fidélité au sens s'oppose - comme chez le croyant et le philosophe - à la fidélité à la lettre. Oui, la fidélité au sens est obligatoirement une infidélité à la lettre.

Mais cette infidélité à la lettre étrangère est nécessairement une fidélité à la lettre propre. Le sens est capté dans la langue traduisante. Pour cela, il faut qu'il soit dépouillé de tout ce qui ne se laisse pas transférer dans celle-ci. La captation du sens affirme toujours la primauté d'une langue. Pour qu'il y ait annexion, il faut que le sens de l'œuvre étrangère se soumette à la langue dite d'arrivée [...]. Et telle est l'essence de la traduction ethnocentrique ; fondée sur la primauté du sens, elle considère implicitement ou non sa langue comme un être intouchable et supérieur, que l'acte de traduire ne saurait troubler.

7 «Pero, entonces, ¿qué caminos puede emprender el verdadero traductor, que quiere aproximar de verdad a estas dos personas tan separadas, su escritor original y su propio lector, y facilitar a este último, sin obligarlo a salir del círculo de su lengua materna, el más exacto y completo entendimiento y goce del primero? A mi juicio, sólo hay dos. O bien el traductor deja al escritor lo más tranquilo posible y hace que el lector vaya a su encuentro, o bien deja lo más tranquilo posible al lector y hace que vaya a su encuentro el escritor». 
Il s'agit d'introduire le sens étranger de telle manière qu'il soit acclimaté, que l'œuvre étrangère apparaisse comme un « fruit » de la langue propre. ${ }^{8}$

Como contraposición a la traducción etnocéntrica, Berman (1999: 74) sostiene que la traducción debe tener un propósito ético y ajustarse a los valores de fidelidad y exactitud. Para el autor, el acto ético consiste en reconocer y recibir al «otro» como «otro». De esto se desprende, por tanto, que el traductor considera más apropiada la traducción literal, aunque no profundiza en los procedimientos de traducción a los que se puede recurrir.

Con respecto a las opciones metodológicas de las que dispone un traductor para desempeñar su tarea, Venuti (2010: 69) se refiere a la formulación de Schleiermacher acerca de la existencia de dos métodos de traducción: o bien el traductor «deja al autor en paz y acerca el lector a él», o bien «deja al lector en paz y acerca el autor a él». Para Venuti, Schleiermacher está permitiendo al traductor optar entre un método de domesticación (reducción etnocéntrica del texto extranjero a los valores culturales de la lengua meta, al «traer a casa al autor») y un método de extranjerización (una desviación de los valores que marcan la diferencia cultural y lingüística en el texto original para «enviar al lector al extranjero»). Con respecto a la solución a este problema, Venuti (2008: 15) sostiene que el traductor literario independiente siempre puede escoger el grado y la dirección de la «violencia» del acto de traducir. Estos dos métodos de traducción indican, de acuerdo con Venuti (2008: 19), actitudes éticas hacia el texto y la cultura extranjera, no actitudes de carácter discursivo relativas a la fluidez o naturalidad del texto. Se trata, no obstante, de una postura extrema y prescriptiva con un enfoque sociocultural que denuncia la apropiación cultural de los textos.

El traductólogo bíblico Nida, sin embargo, opta por una aproximación más comunicativa y centrada en el mensaje. A propósito de la equivalencia en traducción, Nida (1964: 159) señala que pueden citarse dos tipos: la equivalencia formal y dinámica. La equivalencia formal se centra en el mensaje, en su forma y contenido. El traductor trata de reproducir en la lengua meta el mensaje en lengua original de la manera más literal y cercana posible, de forma que se recurre constantemente a la comparación entre ambos textos para evaluar la

8 «La fidelidad al sentido se opone (como ocurre con el creyente y el filósofo) a la fidelidad a la letra. Sí, la fidelidad al sentido constituye obligatoriamente una infidelidad a la letra.

Pero esta infidelidad a la letra extranjera es necesariamente una infidelidad a la letra propia. La lengua que traduce capta el sentido. Para ello, es necesario que se despoje de todo lo que no se deja transferir en ella. La captación del sentido afirma siempre la primacía de una lengua. Para que se produzca la anexión, es preciso que el sentido de la obra extranjera se someta a la denominada lengua de llegada [...]. Y esta es la esencia de la traducción etnocéntrica: al basarse en la primacía del sentido, considera implícitamente o no su lengua como un ser intocable o superior que el acto de traducción no puede alterar. Consiste en introducir el sentido extranjero de tal manera que sea aclimatado, que la obra extranjera parezca un "fruto" de la propia lengua» [traducción propia]. 
precisión y corrección. Por otro lado, la traducción que persigue la equivalencia dinámica se basa en el principio de búsqueda de un efecto equivalente. En este tipo de traducción, el traductor no se concentra en reproducir exactamente el mensaje original, sino en la relación dinámica que se establece entre el receptor y el mensaje y en reproducirla en el texto meta. Así, una traducción dinámica tiene como objetivo una naturalidad completa de expresión y un acercamiento a la cultura del receptor, en lugar de explicar la cultura original (Nida 1964: 159). Así pues, Nida y Taber consideran que debe priorizarse la equivalencia dinámica a la correspondencia formal, que caracterizan del siguiente modo (Nida y Taber 1969: 24):

Dynamic equivalence is therefore to be defined in terms of the degree to which the receptors of the message in the receptor language respond to it in substantially the same manner as the receptors in the source language. This response can never be identical, for the cultural and historical settings are too different, but there should be a high degree of equivalence of response, or the translation will have failed to accomplish its purpose. ${ }^{9}$

A pesar del interés de estas teorías desde un punto de vista sociocultural y comunicativo, se trata en la mayoría de los casos de posturas prescriptivas y dicotómicas, que sitúan la tarea de traducción en una encrucijada en la que debe optarse por anexar culturalmente un texto a una cultura meta o mantener su idiosincrasia original y presentarlo con todo su exotismo, sin tener en cuenta gradaciones o escalas grises. Si bien las estrategias de «naturalización» y «extranjerización» se llevan a cabo de manera incuestionable en traducción (a pesar de que no conllevan las mismas implicaciones y consecuencias en todos los tipos de textos), dejan de lado numerosos factores comunicativos y culturales que rodean el acto de traducción. Aunque constituyen aportaciones valiosas en la reflexión teórica sobre la traducción, estas teorías ignoran, en general, la variedad de situaciones comunicativas y numerosos aspectos pragmáticos como la función y la intención del texto meta, el encargo de traducción y el público al que va dirigido, así como el canon cultural de una determinada época o los movimientos estético-literarios predominantes en el momento de la traducción. Consideramos, pues, que es preciso estudiar la equivalencia traductora y el método de traducción siguiendo un enfoque descriptivo que permita dar cuenta de los diferentes tipos de traducción que se producen en los distintos contextos, teniendo en cuenta los diversos factores pragmáticos.

Por otra parte, a la luz de estas teorías, puede constatarse cómo la postura de Tolkien ante la traducción varía progresivamente desde la defensa de una

\footnotetext{
9 «Por lo tanto, la equivalencia dinámica se define según el grado en que los receptores del mensaje en la lengua receptora responden a este sustancialmente de la misma manera que los receptores de la lengua origen. Esta respuesta no puede ser nunca idéntica, ya que el contexto cultural e histórico es distinto, pero debería haber un alto grado de equivalencia en la respuesta, o la traducción habrá fallado en el cumplimiento de su propósito» [traducción propia].
} 
traducción marcadamente «exotizante» o «extranjerizante» de su obra (es decir, en la que se privilegian los aspectos formales y se acerca el receptor al autor, o se preservan en mayor medida los elementos propios de la cultura original) a una postura más «domesticante» o «naturalizante» en su manuscrito «The Nomenclature of The Lord of the Rings» (en la que acepta que se produzca un acercamiento a la cultura y la lengua de llegada y se traduzca la nomenclatura que tiene un significado en inglés para poder recrear un efecto similar al del texto original en la cultura receptora mediante una equivalencia dinámica). No obstante, lo que Tolkien propone en su manuscrito no puede considerarse tampoco una traducción totalmente «naturalizante», puesto que solo defiende trasvasar el contenido semántico para que el receptor meta tenga la misma información que el receptor original (acercándose así al concepto de equivalencia dinámica de Nida y Taber). Una traducción «naturalizante», según las teorías que acaban de exponerse, implicaría una transformación profunda de la obra, en la que las resonancias culturales a la historia inglesa y las redes lingüísticas emparentadas con el inglés se verían sustituidas por el pasado cultural, histórico y lingüístico de otras culturas. Por tanto, es preciso justificar y defender la necesidad de tener en cuenta otros factores y niveles de gradación de apropiación cultural de una traducción.

\subsection{La aplicación de la reflexión traductológica actual a la traducción de la obra de Tolkien}

Uno de los autores más destacados que abogan por una postura ecléctica, variable según los factores pragmáticos y comunicativos, es Umberto Eco, que entiende la traducción como un proceso de negociación del traductor con el texto (así como con el resto de los agentes que intervienen en el acto comunicativo). Del mismo modo, el significado de una traducción también forma parte de este proceso de negociación porque, al traducir, negociamos el significado que la traducción debe expresar (del mismo modo que en nuestra vida diaria negociamos el significado que atribuimos a las expresiones que utilizamos) (Eco 2007: 102-103). Así pues, la equivalencia constituiría un valor relativo que debería negociarse según la situación y el contexto comunicativo.

No obstante, conviene resaltar, por su importancia en cuanto al cambio de concepción de 'equivalencia' y a la introducción de la noción de 'adecuación', los enfoques funcionalistas y, particularmente, la teoría del skopos. En este sentido, Reiss (2009: 143-144) señala que 'adecuación' puede asociarse de manera aproximativa al concepto de pertinencia, que a su vez no constituye un concepto absoluto, puesto que la pertinencia o adecuación debe establecerse según la finalidad de la acción llevada a cabo. Es decir, en el caso de la traducción, las elecciones del traductor serán adecuadas si responden a la finalidad asignada a la traducción. Se trata, pues, de una función basada en el proceso. Sin embargo, el término 'equivalencia' designa la relación entre dos 
productos (en este caso, el producto original y el producto meta). En este sentido, Reiss (2009: 144) resalta la importancia de ambos conceptos, ya que puede ocurrir que el objetivo que se asigna a una traducción sea diferente del objetivo del texto meta, lo que alterará la relación de equivalencia entre ambos productos.

Asimismo, en su obra conjunta con Vermeer, los autores plantean, como base de su teoría del skopos, que todo texto se crea con un propósito más o menos específico: se trata de una acción llevada a cabo en relación con otras personas para alcanzar un objetivo. De este modo, tanto el emisor como el receptor del texto forman parte de la situación comunicativa, y a su vez se ven limitados por la comunidad sociocultural en la que viven, lo que afecta también a la producción del texto. Así, para los autores, la «situación» consiste en los siguientes factores: el trasfondo cultural, el contexto en que se desarrolla la interacción, las circunstancias psicológicas y sociales de los agentes que intervienen en la comunicación y la relación que existe entre ellos (Reiss y Vermeer 2013: 17). En este sentido, Reiss y Vermeer (2013: 85-86) plantean que una teoría de la acción de traducción debe partir de una situación que siempre incluye una acción precedente (el texto origen); es decir, la cuestión no reside en cómo se produce la acción sino en cómo continúa dicha acción en la traducción. Por lo tanto, las decisiones de traducción se basan en un principio fundamental que no solo determina lo que se trasvasa, sino cómo se trasvasa en función del objetivo. Este propósito u objetivo es lo que los autores denominan el skopos de la traducción.

Conviene citar, por su alusión explícita a la traducción de nombres propios de la ficción, la aportación teórica de Virgilio Moya (1993: 237). A propósito de la traducción de nombres de ficción, el autor señala que en español no existe una regla fija que determine si se debe adaptar el nombre o transcribirlo. Distingue, en este sentido, dos tipos de nombres: «aquellos con una carga de significación imperceptible en su signo y los que presentan una traducción transparente» (Moya 1993: 237-238). En el primer caso (por ejemplo, Albertine de Proust), el autor aboga por transcribirlos simplemente (es decir, mantenerlos como en el texto original). En el segundo caso se incluirían nombres con carga semántica, como Baisecul de Rabelais o Ido del Sagrario de Galdós, así como nombres alegóricos como Justicia. A este respecto, Moya (1993: 238) defiende que deben traducirse:

En el caso de los nombres de Rabelais, yo me inclinaría por traducirlos a la lengua terminal, para luego terminar ajustándolos a la fonética de la lengua original, en este caso la francesa. Así, Baisecul podría dar "Lamecul".

Por tanto, Moya (1993: 239) establece la siguiente regla para los nombres propios de personajes de ficción: «a mayor carga simbólica del signo del nombre mayor es la obligación de traducirlo». 
Desde nuestro punto de vista, si bien es preciso (e inevitable, como ocurre en el caso de la traducción de la nomenclatura de Tolkien) en muchos casos adoptar estrategias que tienden a la «naturalización» o a la «extranjerización», estas opciones de traducción no dependen de factores prescriptivos o de una manera más apropiada o correcta de traducir por sí misma (dependiente únicamente de valores éticos, formales o semánticos), sino en gran medida del contexto de producción de la traducción, la situación comunicativa y la función que desempeñará la traducción, entre otros.

Por lo que respecta a la obra de Tolkien de manera particular, aunque los elementos filológicos son fundamentales y la intención original del autor es presentar un mundo ficcional que evoque la cultura inglesa (en mayor o menor medida, puesto que no deja de tratarse de un mundo ficcional que representa un mundo distinto del mundo real) y que está destinado a su lectura para entretenimiento por parte de un público general, si se pretende publicar un texto con una función similar en otra cultura determinados elementos deberían adaptarse para adecuarse a esta función equivalente. De lo contrario, la función variará y dará lugar a una traducción de carácter filológico o erudito (si se preservan todos los nombres originales y se añaden notas al pie o glosarios en los que se explique el origen etimológico, como sugería Tolkien en sus primeras cartas) o bien a una adaptación o reescritura (si el traductor cambiara y alterara toda la red lingüística para adaptarla, por ejemplo, a la cultura española, de modo que la obra original se vería profundamente alterada). En estos casos, la elección de un método u otro debe estar asociada a la función que desempeñará la traducción y el propósito para el que se publica, por lo que el traductor deberá negociar los valores semánticos o formales fundamentales que deben trasvasarse en relación con todos los agentes que intervienen en la traducción (incluido el autor y su intención).

En este sentido, resulta útil e ilustrativa, a nuestro modo de ver, la explicación filológica que Tolkien ofrece en «The Nomenclature of The Lord of the Rings», ya que sugiere un modo de traducir su nomenclatura que puede ayudar a eludir la dicotomía entre traducción literal y libre, «exotizante»o «naturalizante» $u$ orientada al receptor o al autor (suponiendo que se aplique a una situación de traducción en la que el texto resultante cumpla la misma función que el texto original, lo que en principio resultaría más probable al traducir una obra de ficción). Aunque esta guía defiende implícitamente un método más «naturalizante» por parte de Tolkien (en comparación con sus escritos previos), si se parte de una función idéntica con destinatarios similares en la lengua de llegada, las indicaciones de Tolkien permiten traducir la obra sin caer en una «extranjerización» extrema (con una traducción erudita o filológica) ni en la «naturalización» total (con la reescritura de la obra y la identificación de nombres con otra cultura diferente). Según esta guía, el traductor debe tratar siempre de trasvasar los rasgos formales y semánticos, de forma que se recreen los efectos y el significado que produce un nombre en el 
texto original con un resultado equivalente en el texto meta. Así, si el nombre original tiene un significado en inglés, sería conveniente que este significado sea también reconocible para el lector en otra lengua; sin embargo, si se trata de un nombre procedente de una lengua ficcional o cuyo significado es obscuro (como en el caso del inglés antiguo) para el receptor, el traductor puede mantenerlo para preservar la coherencia denominativa del entramado lingüístico creado para el mundo ficcional. En los casos en los que el nombre en inglés no tenga un significado relevante en relación con la obra (por ejemplo, el antropónimo William), se puede mantener en inglés para preservar el color local. Así, pues, retomando el concepto de negociación de Umberto Eco, será necesario evaluar qué valores deben trasvasarse en el texto meta para cumplir con el objetivo de la traducción produciendo un resultado equivalente que mantenga, en la medida de lo posible, las complicadas relaciones lingüísticas y filológicas que establece Tolkien en su obra, a la vez que transmita toda la información semántica reconocible por el lector original al lector del texto meta. Habrá que tenerse en cuenta, además, el grado de cercanía entre ambas culturas y lenguas (la del texto original y meta).

A modo de ejemplo, podemos tomar el nombre del personaje Bilbo Baggins. El traductor, al interpretar el texto original, puede determinar que los rasgos fundamentales de este nombre para definir al concepto ficcional que designa son: <nombre de personaje masculino inventado sin carga semántica $>+$ <apellido inventado formado por una raíz con carga semántica (bag-)> y <una terminación propia de apellidos en lengua inglesa (-ins)>. La raíz semántica bagestá relacionada, además, con el lugar en el que habita el personaje, Bag-End. Eventualmente (aunque podría resultar una apreciación subjetiva $y$, en cualquier caso, secundaria en la negociación de los valores fundamentales que deben traducirse), podría destacarse la aliteración del sonido $b$ que puede producir un determinado efecto en relación con el personaje al que denomina (un hobbit). En este sentido, el traductor deberá decidir qué elementos son imprescindibles para producir una traducción equivalente (es decir, que cumpla con la misma función). Si observamos, por ejemplo, la traducción al español de El Señor de los Anillos, que lo nombra Bilbo Bolsón, podemos observar que el traductor ha logrado mantener, en este caso, todos los rasgos formales y semánticos para producir un resultado equivalente. Así, puesto que el nombre no posee carga semántica, se ha mantenido; el apellido, por su parte, se ha sustituido por otra raíz con carga semántica (con el mismo significado que la original), bolso-, a la que se ha añadido una terminación que podría corresponder a un apellido en lengua española (-ón). ${ }^{10}$ Esta traducción respeta

${ }_{10}$ Conviene señalar, no obstante, que, mientras que en el Diccionario de la Real Academia Española se registra 'bolsón' como entrada lexicográfica, baggins no se recoge en diccionarios de inglés como el Oxford English Dictionary (en su versión en línea). Podría afirmarse, por tanto, que la traducción española es más «naturalizante», al emplear un vocablo existente en lengua española. 
también la referencia al lugar en que habita el hobbit, que se llama Bolsón Cerrado $\mathrm{y}$, además, se mantiene la aliteración. Esta posibilidad, no obstante, no tiene por qué presentarse en todos los nombres. En el caso del nombre Elrond, cuya formación responde a un sistema lingüístico inventado por el autor (el élfico) y que, por lo tanto, no tiene carga semántica en lengua inglesa, no tendría sentido plantearse qué elementos semánticos será importante trasvasar (puesto que la palabra tiene carga semántica en el sistema lingüístico inventado del élfico, pero no en inglés), por lo que el traductor podría mantener la forma original. Sin embargo, a diferencia de lo que sugiere Tolkien, consideramos que la adaptación morfológica en el caso de nombres en inglés cuyo significado sea obscuro o no reconocible para el receptor (como Took o Gamgee) no tiene por qué realizarse para producir resultados equivalentes, aunque, de nuevo, dependerá de la función de la traducción o los valores fundamentales que se negocien, que en cualquier caso deberían ser coherentes para todos los nombres similares.

\subsection{La traducción al español de The Lord of the Rings}

En el caso concreto de la traducción al español, en trabajos anteriores (Moreno Paz, 2019a) se esbozó el panorama del estado actual de las traducciones y de la investigación académica en traducción en torno a la obra de Tolkien. Su mundo ficcional, que comprende más obras además de The Lord of the Rings, ha sido traducido al español por la editorial Minotauro en las últimas décadas, aunque las traducciones se han llevado a cabo por distintos traductores.

Sin mencionar The History of Middle-earth (una colección de 13 volúmenes de carácter más enciclopédico que narrativo) el mundo ficcional creado por Tolkien se presenta en The Hobbit (1937), The Lord of the Rings (1954-1955), The Adventures of Tom Bombadil (1962), Bilbo's Last Song (1974), The Silmarillion (1978), Unfinished Tales of Númenor and Middle-earth (1980), The Children of Húrin (2007), Beren and Lúthien (2017) y The Fall of Gondolin (2018). ${ }^{11}$

Las traducciones al español se publicaron, respectivamente, como El hobbit (trad. de Manuel Figueroa, 1982), El Señor de los Anillos (Luis Domènech y Matilde Horne 1977-1978), El Silmarillion (Rubén Masera y Luis Domènech 1984), Las aventuras de Tom Bombadil (traducción colaborativa por parte de traductores aficionados y no profesionales, en 2005), La última canción de Bilbo (Manuel Matas 2010), Cuentos inconclusos de Númenor y la Tierra Media (Rubén Masera 1990), Los hijos de Húrin (Estela Gutiérrez 2007), Beren y Lúthien (Martin Simonson, Rubén Masera, Teresa Gottlieb, Luis Domènech, Estela Gutiérrez, Elías Sarhan y Ramón Ibero 2018) y La caída de Gondolin (Martin Simonson 2019). ${ }^{12}$

\footnotetext{
${ }^{11}$ Sin embargo, las dos únicas obras que vieron la luz en vida de J. R. R. Tolkien fueron The Hobbit y The Lord of the Rings. El resto de las obras se editaron y publicaron de forma póstuma por su hijo Christopher Tolkien.

${ }^{12}$ Para más información sobre las traducciones al español, véase Moreno Paz (2019a).
} 
La intervención de tantos traductores en las versiones al español pone de relieve la falta de homogeneización en la traducción de su obra, en la que se dan numerosos casos de incoherencias denominativas entre unas obras y otras. Un ejemplo es el nombre de los hobbits Burrows y Grubb, que aparecen traducidos en El hobbit como Borgo y Gorgo y en El Señor de los Anillos como Madriguera y Cavada. ${ }^{13}$ Sobre las traducciones al español, además de haber sido realizadas por personas diferentes, es posible constatar que no se llevaron a cabo cronológicamente y, sobre todo, que el desfase entre algunas publicaciones y sus traducciones conllevó en algunos casos incluso décadas (cabe destacar la diferencia de 45 años entre la publicación original de The Hobbit y su traducción o de 23 años entre The Lord of the Rings y la versión de Minotauro).

Por otro lado, puesto que todas las traducciones son posteriores a la publicación de «The Nomenclature of the Lord of the Rings», cabe asumir que los traductores tuvieron acceso a la guía de Tolkien. Si bien se trata solo de pautas que ofrece Tolkien, se observa que se siguen en gran medida en El Señor de los Anillos. Encontramos, pues, nombres propios que tienen un contenido semántico en inglés y cuyo sentido se trasvasa al español, como Valle de la Raíz Negra (Blackroot Vale), Bárbol (Treebeard) o Brandivino (Brandywine). Sin embargo, no ocurre en todos los casos, de modo que nombres como Rivendell (literalmente, 'valle hendido') se adapta morfológicamente como Rivendel, por lo que pierde contenido semántico en español. También se mantienen los nombres en lenguas inventadas en la traducción al español, como Galadriel o Minas Tirith, y se adaptan morfológicamente nombres que Tolkien recomienda naturalizar en la lengua de llegada, como Tuk (de Took) o Gamyi (de Gamgee).

En otros casos, sin embargo, se ignoran las recomendaciones de Tolkien, por ejemplo, al respecto de la preservación de los nombres procedentes del inglés antiguo (que, según Tolkien, era preferible preservar como en el texto original para mantener el carácter arcaico del nombre). Así, por ejemplo, Windfola se traduce en español como Hoja de Viento. Estas recomendaciones se ignoran también al omitir 759 nombres propios en la traducción al español, por lo que se reduce la información y el contenido semántico de la obra al receptor hispanohablante. Además, conviene resaltar que se producen numerosas incoherencias denominativas entre las distintas obras o dentro incluso de la

13 Sería interesante, en futuros trabajos, profundizar en el número de incoherencias denominativas que se dan según las obras y en la adecuación de las distintas opciones, con vistas al planteamiento de un posible proyecto de retraducción de la obra de Tolkien al español para homogeneizar el mundo ficcional (como se está realizando actualmente en Francia por el equipo de traducción coordinado por el profesor universitario Vincent Ferré y encabezado por el traductor Daniel Lauzon). 
misma obra, lo que revela falta de consenso y atención a la nomenclatura en numerosas ocasiones. ${ }^{14}$

\section{CONCLUSIONES}

La obra de Tolkien supone un reto para la traducción desde el punto de vista filológico, debido al entramado lingüístico creado por el autor para representar pueblos, razas y lugares de su mundo ficcional, no solo a partir de lenguas reales, sino también de lenguas ficcionales. Estas relaciones lingüísticas se manifiestan especialmente en la creación de su nomenclatura, que pone de relieve la importancia de los aspectos filológicos en su obra (que constituyen, como se ha adelantado previamente, su principal motivación para escribirla). Su faceta de filólogo, profesor y traductor se manifiesta asimismo en su escrito "The Nomenclature of The Lord of the Rings», donde ofrece pautas para traducir la nomenclatura de su obra y que resulta, al margen del método de traducción propuesto, un documento útil en lo relativo a las explicaciones filológicas que ofrece, así como una posible fuente de documentación etimológica para el traductor.

A pesar de mostrarse reticente en un primer momento a la traducción de cualquier nombre de su obra (con la justificación de que alteraría el «color local» pretendidamente inglés que había querido otorgarle), al comprobar la inviabilidad de su propuesta (ya que en otros países optaban por traducir la nomenclatura que tenía significado en inglés), la postura de Tolkien hacia la traducción cambia hacia una posición más «naturalizante», según la cual el traductor debería recrear el contenido semántico reconocible en la lengua de la traducción para producir el mismo efecto. En este sentido, si bien consideramos que se trata de una propuesta de mayor utilidad (dado que de este modo el receptor dispone del mismo contenido semántico que el lector original, acercándose así la traducción a la adecuación según la función que persigue), es preciso realizar algunas matizaciones.

En primer lugar, no puede decirse que la traducción «naturalizante» sea un método más apropiado por sí mismo (atendiendo a un enfoque descriptivo), pues es necesario estudiar la traducción también según sus coordenadas situacionales y pragmáticas para observar cuál es la función y el propósito del texto. Si la función pretende ser la misma que la del texto original (es decir, lúdica y expresiva, como obra de ficción destinada a un público general), entonces cabe asumir que el lector del texto meta debería tener una experiencia de lectura similar a la del lector del texto original, por lo que los nombres con contenido semántico reconocible deberían traducirse. No se podría hablar,

\footnotetext{
14 Véase, a este respecto, Moreno Paz (2019b), donde se analizan los procedimientos de formación utilizados en la creación de nombres propios en El Señor de los Anillos y se mencionan las incoherencias denominativas que se producen en esta obra.
} 
desde nuestro punto de vista, de una traducción totalmente «naturalizante», ya que en el caso de la obra de Tolkien esto implicaría alterar toda la red lingüística y modificar las relaciones entre las lenguas (por ejemplo, los pueblos que hablan una lengua emparentada con el inglés como el inglés o el nórdico antiguos pasarían a hablar francés antiguo, latín o castellano antiguo, si la lengua meta fuera el español, por ejemplo). Esta opción, a no ser que respondiera a una función del texto diferente a la obra original (una imitación, adaptación o reescritura) no resultaría, por tanto, adecuada, al alterar la recepción de una obra anclada en unas coordenadas culturales determinadas. La opción que propone Tolkien en su manuscrito, sin embargo (a pesar de obviar las variables pragmáticas y situacionales), parece ser más adecuada para una traducción con una función similar, de modo que se intenta que el receptor del texto meta disponga de la misma información semántica que el lector original, sin por ello alterar la red lingüística de la obra radicalmente (si bien es cierto que, al sustituir los nombres en inglés moderno por otras lenguas, como el francés, se pierde la conexión con lenguas emparentadas como el inglés antiguo o el nórdico antiguo, pero se preserva el «color local» en estos nombres). Se negocia, por tanto, que el valor semántico denotativo para comprender el texto ficcional es primordial con respecto a otros valores formales, que en algunos casos deben sacrificarse para producir un texto con una función similar en otra lengua.

No obstante, conviene recordar que, en muchos casos, las opciones de traducción escogidas no dependen únicamente de la reflexión o estrategias procedimentales adoptadas por el traductor, sino también en gran medida de la decisión editorial y el propósito con el que se publica la traducción, por lo que es necesario resaltar que, en el caso de la traducción de la obra de Tolkien con la misma función en otras lenguas, idealmente deberían tenerse en cuenta sus apuntes filológicos para poder ofrecer una traducción cuya calidad se adecue al texto original, ya que en caso de no tener en cuenta la importancia de la filología en su obra se estaría reduciendo considerablemente su valor artístico y literario y su idiosincrasia en la historia de la literatura y, concretamente, de la literatura fantástica moderna.

En el caso concreto de la traducción al español, El Señor de los Anillos fue la primera obra del autor en ser publicada en español. La edición corrió a cargo de Minotauro y se tradujo conjuntamente por Luis Domènech (sobrenombre del propio editor, Francisco Porrúa) y Matilde Horne en 1977 (23 años después de la publicación original). A pesar de que en esta época la guía de Tolkien sobre la traducción de su obra ya estaba publicada, los traductores no siempre siguieron sus instrucciones, optando por diferentes técnicas de traducción, traduciendo un mismo nombre de distintas maneras o, simplemente, omitiéndolo. Convendría, pues, profundizar en futuros trabajos sobre la necesidad de una nueva traducción de esta obra según la adecuación de la traducción, en la que debería tenerse presente, sin duda, el manuscrito «The Nomenclature of The 
Lord of the Rings», no solo para mantener y respetar la intención del autor de la obra, sino fundamentalmente para conseguir una traducción coherente, homogénea y documentada en relación con la etimología y formación de la nomenclatura original.

\section{BIBLIOGRAFÍA}

BERMAN, A. (1999), La traduction et la lettre ou l'auberge du lointain, París, Éditions du Seuil.

CARPENTER, H. (1981), Letters of J. R. R. Tolkien, London, George Allen \& Unwin.

CARPENTER, H. (2006), The Letters of J. R. R. Tolkien, London, Harper Collins.

CARPENTER, H. (2016), J. R. R. Tolkien: A Biography, London, Harper Collins.

ECO, U. (2007), Dire presque la même chose : expériences de traduction, París, Bernard Grasset (trad. de Bouzaher, M., Dire quasi la stessa cosa: Esperienze di traduzione, Milán, Bompiani, 2003).

HAMmond, W. G. Y SCUll, C. (2005), The Lord of the Rings: A Reader's Companion, Boston-New York, Houghton Mifflin Company.

Moreno PAZ, M. C. (2019a), «Panorama actual de las traducciones y de la investigación académica en traducción sobre J. R. R. Tolkien al español y al francés», Estudios Franco-Alemanes, 11, 113-136.

Moreno PAZ, M. C. (2019b), «Los irrealia en The Lord of the Rings de J. R. R. Tolkien y su traducción al español: procedimientos de formación y su recurrencia $\mathrm{y}$ productividad», Skopos, 10, 133-159.

MOYA, V. (1993), «Nombres propios: su traducción», Revista de Filología de la Universidad de la Laguna, 12, 233-247.

NIDA, E. A. (1964), Toward a Science of Translating: with special reference to principles and procedures involved in Bible translating, Leiden, E. J. Brill.

NIDA, E. A. Y TABER, C. R. (1969), The Theory and Practice of Translation, Leiden, E. J. Brill.

REISS, K. (2009), Problématiques de la traduction, París, Economica-Anthropos (trad. y notas de Bocquet, C. A., Grundfagen der Ubersetzungswissenschaft, Viena, WUTUniv.-Verl., 1995).

REISS, K. Y VERMEER, H. J. (2013), Towards a General Theory of Translational Action: Skopos Theory Explained, Manchester, St Jerome Publishing (trad. de Nord, Ch., Grundlegung einer allgemeinen Translationstheorie, Berlín, De Gruyter, 1984).

SCHLEIERMACHER, F. D. E. (2000), Sobre los diferentes métodos de traducir, Madrid, Gredos (trad. de García Yebra, V., Über die verschiedenen Methoden des Übersezens, Berlín, Königlichen Akademie der Wissenschaften, 1813).

TOLKIEN, J. R. R. (2007 [1955]), The Lord of the Rings, London, Harper Collins.

TURNER, A. (2005), Translating Tolkien: Philological Elements in The Lord of the Rings, Berna, Peter Lang.

TURnER, A. (2011), «A Theoretical Model for Tolkien Translation Criticism», en Tolkien in Translation, Honegger, T. (ed.), Zurich, Walking Tree Publishers, 1-30.

VenUTI, L. (2008²), The Translator's Invisibility, London-New York, Routledge.

VENUTI, L. (2010), «Translation as cultural politics: Regimes of domestication in English», en Critical Readings in Translation Studies, Baker, M. (ed.), London-New York, Routledge, 65-79. 